DR. EDWIN R. HEATH, to whom we referred some time ago as intending to take up the work of South American exploration commenced by Prof. Orton, and interrupted by his untimely death, left New York on November 18 , on the William H. Keeney, for Pará, expecting to proceed by steamer to San Antonio, to remain there during the winter, and from that point as a centre to carry on his further investigations. In these he expects to be greatly assisted by Messrs. T. and P. Collins, of Philadelphia, the contractors for the Mamore and Madera Railroad.

THE Woodruff half-educational, half-pleasure expedition round the world has been again organised on a new basis. A steamer of 3,000 tons has been purchased in Europe, and the inclusive fare is 2,500 dollars.

MR. S. E. PEAL communicates to the Indian Tea Gazette some remarks on the subject of an overland route to China, via the Assam Valley, which are of interest, as there is no attempt to under-rate the great difficulties to be encountered. He justly observes that the merits of the various passes out of Eastern Assam are not well understood, and that it is comparatively easy to draw a line on the map from some point in Upper Assam to the Yangtoze or Likiang-fu, and to say, "Why cannot this be done?" Wilcox and others since have sufficiently shown the difficult nature of the country, viâ the Tengapani and the Brahmaputra Valley; what lies beyond the point explored is reputed still worse, and as crossing snow. Northwards again, vita the Dihong, or Dihong Gorges, the outlet is equally uninviting. The Upper Subansire, or Lopra-cha-chu, is not well explored, though routes not far from it are known to pass for threequarters of a mile along the face of a precipice 1,500 feet above an abyss, and on a path of stone slabs resting on iron piers let into the face of the rock. The Towang route is, again, difficult, and too far west. South of the Tengapani we have Dapha Búm, I4,500 feet high, with a pass to the south, in which Wilcox's experiences prove how unsuitable it would be for a trade-route. South of Daphapani is the upper portion of the Buri Dihing, and whether there is a route up it crossing Eastern Patkai and going down the Sitka, is not known, though Singphús travel that way. It is one of the routes to be explored, and may give a pass at, perhaps, 5,ooo feet elevation or less. The Namrup basin, however, would so far seem to be the only reliable and easy outlet from Eastern Assam : and here is a pass at an elevation of about $\mathrm{I}, 000 \mathrm{ft}$., leading viâ Hukong and the Shoemai direct to Western Yünnan, a route which is at present in use. By the Patkai route past Nongyang Lake to the Hukong Valley, Mr. Peal says, we cross at the highest an elevation of 1,500 to $2,000 \mathrm{ft}$., and fall at once into a beaten track to Yünnan. By this route alone also can the huge snow-clad ridges be turned that stand as barriers east and west of the Upper Irrawadi or Shoemai, and that stretch down from the north to about the parallel of $27^{\circ}$. In point of fact the east-south-east is the only direction in which it is possible to get out of Assam in the direction of China at less than 2,000 ft. above the sea-level.

\section{THE COMPOUND NATURE OF THE} ELEMENTS

WE have not yet received from the Royal Society the paper read last Thursday by Mr. Lockyer, in which he brought forward facts indicating the compound nature of the chemical elements. In the meantime the following article from yesterday's. Times may be of interest ; it is evidently written by a chemist who was present when the paper was read :-

"At a crowded meeting such as is seldom witnessed of the Royal Society, on Thurstay evening last; Mr. J. Norman Lockyer, F.R.S., read a lengthy paper, in which he discussed the evidence derived from spectroscopic observation of the sun and stars and from laboratory experiments, which has led him to the conclusion that the so-called elements of the chemist are in reality compound bodies. In order that the line of argument followed by Mr. Lockyer may be understood, it will be necessary briefly to refer to the results of previous researches. As a rule, in observing spectra, the substance to be examined is volatilised in a gas flame or by means of sparks from an induction-coil, and the light is allowed to fall on the slit of the spectroscope; the spectrum is then generally one in which the lines run across the entire field, but by interposing a lens between the spark apparatus and the slit of the spectroscope, Mr. Lockyer was enabled to study the various regions of the heated vapour, and thus to establish the fact, already noted by some previous observers, but to which little attention had been paid, that all the lines in the spectrum of the substance volatilised did not extend to equal distances from the poles. He then showed by the aid of this method that in the case of alloys containing different proportions of two metals, if the one constituent were present in very small quantity, its spectrum was reduced to its simplest form, the line or lines longest in the spectrum of the pure substance alone appearing, but that on increasing the amount of this constituent its other lines gradually appeared in the order of their lengths in the spectrum of the pure substance. Similar observations were made with compound boclies. It was also noticed that the lines furnished by a particular substance varied not only in length and number, but also in brightness and thickness, according to the relative amount present. Armed with these facts, and with the object of ultimately ascertaining, more definitely than has hitherto been possible, which of the elements are present in the sun, Mr. Lockyer, about four years ago, commenced the preparation of a map of a particular region of the spectra of the metallic elements, for comparison with the map of the same region of the solar spectrum. For this purpose about 2,000 photographs of spectra of all the various metallic elements have been taken, and, in addition, more than 100,000 eye observations hare been made. As it is almost impossible to obtain pure substances, the photographs have been carefully compared, in order to elimi nate the lines due to impurities; the absence of a par ticular element as impurity being regarded as proved if its longest and strongest line was absent from the photograph of the element under examination. The result of all this labour, Mr. Lockyer states, is to show that the hypothesis that identical lines in different spectra are due to impurities is not sufficient, for he finds short line coincidences between the spectra of many metals in which the freedom from mutual impurity has been demonstrate. by the absence of the longest lines. He then adds that, five years ago, he pointed out that there are many facts and many trains of thought suggested by solar and stella? physics which point to another hypothesis-namely, that the elements themselves, or, at all events, some of them, are compound bodies. Thus it would appear that the hotter a star the more simple is its spectrum; for the brightest, and therefore probably the hottest stars, such as Sirius, furnish spectra showing only very thick hydrogen lines and a few very thin metallic lines, characteristic of elements of low atomic weight, while the cooler stars, such as our sun, are shown by their spectra to contain a much larger number of metallic elements than stars such as Sirius, but no non-metallic elements; and the coolest stars furnish fluted band-spectra characteristic of compounds of metallic with non-metallic elements and of non-metallic elements. These facts appear to meet with a simple explanation if it be supposed that as the temperature increases the compounds are first broken up into their constituent "elements," and that these "elements" then undergo dissociation or decomposition into 
"elements" of lower atomic weight. Mr. Lockyer next considers what will be the difference in the spectroscopic phenomena, supposing that $\mathrm{A}$ contains $\mathrm{B}$ as an impurity and as a constituent. In both cases $A$ will have a spectrum of its own. B, however, if present as an impurity, will merely add its lines according to the amount present, as we have above explained; whereas if a constituent of $\mathrm{A}$ it will add its lines according to the extent to which $A$ is decomposed and $B$ is set at liberty. So that as the temperature increases the spectrum of $\mathrm{A}$ will fade if $\mathrm{A}$ be a compound body, whereas it will not fade if $\mathrm{A}$ be a true element. Moreover, if $\mathrm{A}$ be $\mathrm{a}$ compound body, the longest lines at one temperature will not be the longest at another. The paper chiefly deals with a discussion from this point of view of the spectrum of calcium, iron, hydrogen, and lithium, as observed at various temperatures; and it is shown that precisely the kind of change which is to be expected on the hypothesis of the non-elementary character of the elements has been found to take place. Thus each of the salts of calcium, so long as the temperature is below a certain point, has a definite spectrum of its own, but as the temperature is raised the spectrum of the salt gradually dies out and very fine lines due to the metal appear in the blue and violet portions of the spectrum. At the temperature of the electric arc the line in the blue is of great intensity, the violet $H$ and $K$ lines, as they are called, being still thin; in the sun the $\mathrm{H}$ and $\mathrm{K}$ lines are very thick, and the line in the blue is of less intensity than either, and. much thinner than in the arc. Lastly, Dr. Huggins's magnificent star photographs show that both the $\mathrm{H}$ and $\mathrm{K}$ lines are present in the spectrum of $\alpha$ Aquilæ, the latter being, however, only about half the breadth of the former; but that in the spectrum of $a$ Lyræ and Sirius only the $\mathrm{H}$ line of calcium is present. Similar evidence that these different lines may represent different substances appears to be afforded by Prof. Young's spectroscopic observations of solar storms, he having seen the $\mathrm{H}$ line injected into the chromosphere seventy-five times, the $\mathrm{K}$ line fifty times; but the blue line, which is the all-important line of calcium at the arc-temperature, was only injected thrice. In the spectrum of iron two sets of three lines occur in the region between $\mathrm{H}$ and $\mathrm{G}$ which are highly characteristic of this metal. On comparing photographs of the solar spectrum and of the spark taken between poles of iron, the relative intensity of these triplets is seen to be absolutely reversed; the lines barely visible in the spark photograph being among the most prominent in that of the solar spectrum, while the triplet, which is prominent in the spark photograph, is represented by lines not half so thick in the solar spectrum. Prof. Young has observed during solar storms two very faint lines in the iron spectrum near $G$ injected thirty times into the chromosphere, while one of the lines of the triplet was only injected twice. These facts, Mr. Lockyer contends, at once meet with a simple explanation if it be admitted that the lines are produced by the vibration of several distinct molecules.

"The lithium spectrum exhibits a series of changes with a rise of temperature precisely analogous to those observed in the case of calcium.

"In discussing the hydrogen spectrum, Mr. Lockyer adduces a number of most important and interesting facts and speculations. It is pointed out that the most refrangible line of hydrogen in the solar spectrum, $h$, is only seen in laboratory experiments when a very high temperature is employed, and that it was absent from the solar protuberances during the eclipse of 1875 , although the other lines of hydrogen were photographed. This line also is coincident with the strongest line of indium as already recorded by Thalén, and may be photographed by volatilising indium in the electric arc, whereas palladium charged with hydrogen furnishes a photograph in which none of the hydrogen lines are visible. By employing a very feeble spark at a very low pressure the $F$ line of hydrogen in the green is obtained without the blue and red lines which are seen when a stronger spark is used, so that alterations undoubtedly take place in the spectrum of hydrogen similar to those observed in the case of calcium. In concluding this portion of his paper Mr. Lockyer states that he has obtained evidence leading to the conclusion that the substance giving the nonreversed line in the chromosphere, which has been termed helium, and not previously identified with any known form of matter, and also the substance giving the $I, 474$ or coronal line, are really other forms of hydrogen, the one more simple than that which gives the $h$-line alone, the other more complex than that which gives the F-line alone.

"There can be no question that the facts brought forward by Mr. Lockyer are of the highest importance and value, and that they will have much influence on the further development of spectrum analysis, to which he has already so largely contributed. But his arguments are of a character so totally different from those ordinarily dealt with by chemists that they will hesitate for the present to regard them as proof of the decomposition of the elements until either they are assured by competent physicists that they cannot be explained by any other equally simple and probable hypothesis, or until what Mr. Lockyer has foreshadowed as taking place to such an extent in other worlds has been realised beyond question or cavil in our own laboratories. It has been suggested that the same molecule may be capable of vibrating in different ways at different temperatures, and thus of yielding different spectra, just as a bell may give out different notes when struck in different ways; and although Mr. Lockyer has replied to this objection, it can scarcely be regarded as finally disposed of. The fact, however, as Mr. Lockyer has pointed out, that the change from the spectrum of a compound to the lowest temperature spectrum of its metallic element is of a similar character to and even less in degree than the change from the lowest temperature spectrum of the metal to the spectra which it furnishes at higher temperatures does not appear to favour such an hypothesis, and from the similarity in the phenomena it is difficult to deny that in both cases decomposition does not equally take place. Prof. Young's observations on the injection of particular lines into the chromosphere during solar storms are also difficult to reconcile with this view, and if the conclusions drawn from previous researches are correct, it also does not account for the short line coincidences which led Mr. Lockyer to his hypothesis.

"Chemists are careful to teach that what are at present regarded as elements are not necessarily simple bodies, but merely substances which they are unable to decompose or which they have no special reason to regard as compound bodies. The remarkable relations, both in atomic weight and properties, existing between many of the elements, tend, indeed, to show that they are related in the manner Mr. Lockyer supposes. We sincerely hope that he will continue his researches in this direction, and we trust that at no very distant time he may be able to bring forward evidence sufficiently clear to convince even the most sceptical."

\section{NOTES}

Mr. J. M. WiLson, Mathematical Master at Rugby School, has been elected Master of Clifton College, in place of Dr. Percival, elected President of Trinity College, Oxford. Mr. Wilson has done very much for science at Rugby, and, although Dr. Percival is a difficult man to follow, and has done more probably than any head master for the teaching of science in schools, still we hope that Mr. Wilson will prove a worthy successor to him. 